\title{
IMPLEMENTATION OF TECHNICAL-TACTICAL TRAINING STRATEGIES FOR ROMANIA'S NATIONAL ICE HOCKEY TEAM
}

\author{
TRANDAFIR Marius, BALINT Lorand \\ Dunărea de Jos University of Galați \\ Transilvania University of Braşov \\ marius.trandafir@ugal.ro \\ lbalint@unitbv.ro
}

\begin{abstract}
In sport, the technical-tactical component is part of the training process of athletes and has a different degree of involvement, depending on the sports branch in question. Ice hockey is a game in which technical-tactical training strategies are decisive in achieving the proposed performance goal. The effectiveness of the implementation of technical-tactical strategies depends mainly on the level of physical training of the team, as this ensures the necessary energy support for the use of tactical elements with higher efficiency indices.

During the study conducted by us, we intend to highlight, for the Romanian national ice hockey team - senior level, the incidence of the technical-tactical strategies that we have designed in achieving the performance objective already set-advancing in a superior Group within the World Ice Hockey Championship. The research methods we used were the following: analysis of the literature of specialty, the observation method, the pedagogical experiment method and the statistical method. The independent variable that we have used consists in the implementation of technical-tactical strategies to Romania's national ice hockey team. The results of the research showed the weight of training components during a competitive year. In the pedagogical experiment that we have conducted, the technical-tactical training has an important place in the training process, the individual and collective technical-tactical training weighing the most. After the final evaluation the technical-tactical training strategies were proven effective and led, along with other components of the training, to the achievement of the targeted objective.
\end{abstract}

Keywords:sports, performance, strategies, technical-tactical, champions

\section{Introduction}

Borrowed from military science, the concept of strategy is defined as a "component of military art, dealing with the preparing, planning, and unfolding of the war and of military operations" (DEX, 1998). Given that sporting events had many times - from Antiquity to the period of the Cold War - a character of confrontation that replaced fighting with weapons, the reprisal of this component within the science of sports and physical education is obvious, at national/ regional/ local level (development strategies), at organisational level (clubs, associations), and mostly at the level of teams. Strategies are projections of a team's path towards an objective, on a long-, medium-, and short-term, transposed in the three types of plans cited by Alexe: plan of perspective, current plan, and operative plan (Alexe, 1993, p. 424).

These premises have acquired a form and a content in the period 1930-1980, through a series of research and publications, which culminated with the 1964 publication of the study Problema antrenamentului sportiv and the 1977 publication of the volume Fundamentals of sports training by Matveyev, who later became the name of reference in the world theory of sports training planning, by defining the concept of periodisation. According to Matveyev (1981), sports 
training should be conditioned by the laws of developing the athlete's training state, namely by athletic form, not by the competitive season and calendar, thus separating the notion of high training state, such as the functions of training: physical, technical, tactical, and psychological.

Mike McGuigan - cited by Joyce and Lewindon- believes that sports performance may be attained by reaching important objectives, such as the improvement of physical, technical, and psychological capabilities, and the development of a rigorously controlled schedule, in order to ensure maximum performance during competitive season and during each major point within a competition (Joyce and Lewindon, 2014, p. 3).

Anatoli Tarasov - the coach believed to be the father of Soviet hockey - states that there are three types of important speeds in ice hockey: the speed of hands, the speed of legs, and the speed of mind; all of them must be trained (Blatherwick, 1994, p. 103).

The performances of top teams in world hockey are not random. For instance, one of the success factors of Canadian hockey players is Hockey Canada Long Term Player Development Plan: Hockey for life, hockey for excellence, a long-term development plan for hockey players in Canada, based on a model designed by IstvanBalyi. It is not only a program of selection or a "strategic" document concerning the development of hockey, but also an eight-stage model of physical, mental, emotional, and cognitive development of athletes and coaches, from play to the podium (Hockey Canada).

The morphological, somatic, functional, mental, physical and technical particularities, the creativity of players and coaches determine the execution manner of a technical procedure, the game style, leading to an efficient execution of a certain procedure (Dragnea and MateTeodorescu, 2002, p. 283; Alexe, 1993, p. 280).

Technical training represents the acquisition by the athlete of technical elements and procedures specific to a sports branch and their assimilation - through systematic instruction - as skills, in order to practice the sport in question in conformity with the game regulations (Flamaropol, 1962, p. 261; Crihan, 1982 p. 105; Alexe, 1993, p. 258; Dragnea et al., 2006, p. 221; Platonov, 2015, p. 577).

According to the aforementioned aspects, the following may be concluded concerning the technique of hockey players: the execution technique of the composing elements depends very much on the development level of the basic and combined motor qualities. Hence, technical skating elements, skating brakes, puck control, puck pass and receive, shoots, fakes, body game, etc, are executed in conditions of high speed and precision, requiring optimal development level of specific power and resistance. In addition, the technical elements executed are in agreement with the individual and collective tactical elements and with the pre-determined technical and tactical strategies.

In what concerns the evaluation and control indicators of technical training, Platonov proposes its evaluation in absolute size (related to the parameters of the model), comparatively (comparing the technique with that of athletes within other sports), in relative size (by relating to values obtained in different environments). Among the evaluation indicators of technical training, the following may be mentioned:

- $\quad$ the volume, namely the number of assimilated elements, procedures, and actions;

- $\quad$ the degree of correct use of the technical skills in the competitive environment, related to those within practices;

- the diversity of technical training, from the perspective of the new identified and acquired skills;

- the stability of technical skills, provided by their degree of correct execution in the presence of perturbing factors, such as fatigue, climate, spectators' behaviour, etc (Platonov, 2001, p. 534).

Authors such as Şiclovan, Dragnea et al., Crihan, Alexe identify a systemic character of the tactics, provided by the principles, ideas, and rules with which the athletes highlight all their technical, physical, psychological capacities in order to solve game situations created by the 
adversaries, the teammates, or the ambience (Dragnea et al., 2006, p. 226; Crihan, 1982, p. 179; Alexe, 1993, p. 271).

Tactical training involves the anticipation of the game's unfolding and the projection of actions meant to ensure victory, involving both the choice of technical procedures and the role of each player in that game sequence. Players should also be trained in order to acquire cognitive skills, such as the capacity of anticipation, the capacity of rapid decision-making and of quick reaction to the actions carried out by colleagues and adversaries.

In the elaboration of technical and tactical instruction strategies implemented in the training of the ice hockey team representing Romania, we have also taken into account aspects concerning the execution of general and specific physical training within the clubs to which the players belong.

As a purpose of the baseline research, we propose to highlight for the representative senior ice hockey team of Romania the incidence of the technical-tactical strategies that we have designed in order to attain the performance objectives proposed (promoting to a higher league within the World Championship).

The working hypothesis that we formulate in agreement with the proposed purpose is the following: the results obtained by the Romanian team at the 2017 Ice Hockey World Championship are determined by the technical and tactical training program, applied within the training and pre-competitive stages.

The research methods used for the experiment are as follows: literature review (which appraised elements of the independent variable); the methods of direct observation of the actions carried out by the subjects within our sample during centralised training; the method of the pedagogical experiment (analysing the impact of the technical and tactical strategy proposed for the competitive year of reference); the statistical method, to compare the means for independent samples: the analysis of the official statistics of the International Ice Hockey Federation.

\section{Experiment framework}

The baseline experiment was carried out within the senior representative ice hockey team of Romania, throughout the competitive year 2017.

In 2016, the senior Ice Hockey World Championship included 47 teams; in 2017, 48 teams were signed up, divided into four value levels (the World Division and the divisions I-III). The World Division of the World Championship comprises 16 teams, divided into two groups each, the first best teams in the world. Romania was in the second Division, group A along with Australia, Belgium, Spain, Iceland, and Serbia, countries that are adversaries in this group. Each of the other divisions includes six teams in two value groups each, except for the last division (Division III), comprising the rest of the teams (7, in 2016 and 8 in 2017), with one group.

In order to finalise the baseline experiment, we have covered the following stages:

First stage: Assessing the circumstances of the baseline experiment

- Determining the team performance objectives (August 2016).

- Analysing the results of the previous season, the 2016 World Championship (September 2016- October 2016).

- Selecting the representative ice hockey team (the research sample) (September 2016October 2016).

Second stage: Applying the independent variable.

- Applying the independent variable - technical and tactical strategies (November 1, 2016April 2, 2017)

Etapa a III-a: Results of the baseline experiment.

- $\quad$ Participating to the World Championship (April 3-9, 2017).

- Analysing the results of the current season, the World Championship 2017 (May - June 2017). 


\section{Applying the independent variable}

In order to attain the pre-determined performance objective for the representative senior ice hockey team of Romania - leading the World Group and promoting to the First Division, Group B - we have proposed a technical and tactical training program concretised in planning documents for the competitive year 2017, addressed to the athletes within the national group. The World Championship was held in April 2017, while in the competitive calendar of that year, no other international or unofficial competitions were organised, which may have provided an opportunity for the representative team to play together. This aspect has determined us to use a methodical strategy for the athletes to train within their club teams. Hence, we have proposed differentiated training programs, the contents of which focused on technical and tactical training. The programs were sent to the clubs to which the athletes within the national groups belonged; they had the form of annual plan, round plans, weekly practice microcycles, starting with the month of November 2016; the athletes would perform the practices with the club coaches. We have focused on the execution of technical and tactical practices manifested as technical elements for goalies, as collective tactics elements, and individual tactics elements. Along with the training programs, we sent a document material - namely a Play Book - that represents a "collection" of exercises and technical and tactical strategies with game situations, from which the coaches - along with the athletes - have extracted the specific exercises to attain the objectives that we have proposed. The other components of training (general and specific physical training; recovery; theoretical training, etc) were performed within the clubs to which the players belong, according to the program proposed by the club coaches and in correlation with our data resulted from the preliminary experiment.

The training plan that we have proposed was carried out as microcycles, which were implemented as follows: the month of November 2016 - 1 week, the month of December 2016 1 week, the month of February 2017 - 1 week. We also mention that the differentiated training plan proposed by us was previously presented to and discussed with the coaches and managers of clubs, thus subsequently confirming the implementation of these instruction strategies.

\section{Research findings and their interpretation}

Within training in the club teams - in the specific preparatory period, according to our strategies - the weighting of the individual and technical training accounted for $47 \%$, compared to the collective tactics training $45 \%$, while technical training accounted for $8 \%$ (Figure 1). The greater weighting of individual technical and tactical training is justified by the fact that - by improving this component - athletes can execute the elements and strategies of collective tactics at a higher level of efficiency. We mention that - in this stage - we have not focused on psychological training, but this component was included in the annual training plan. 


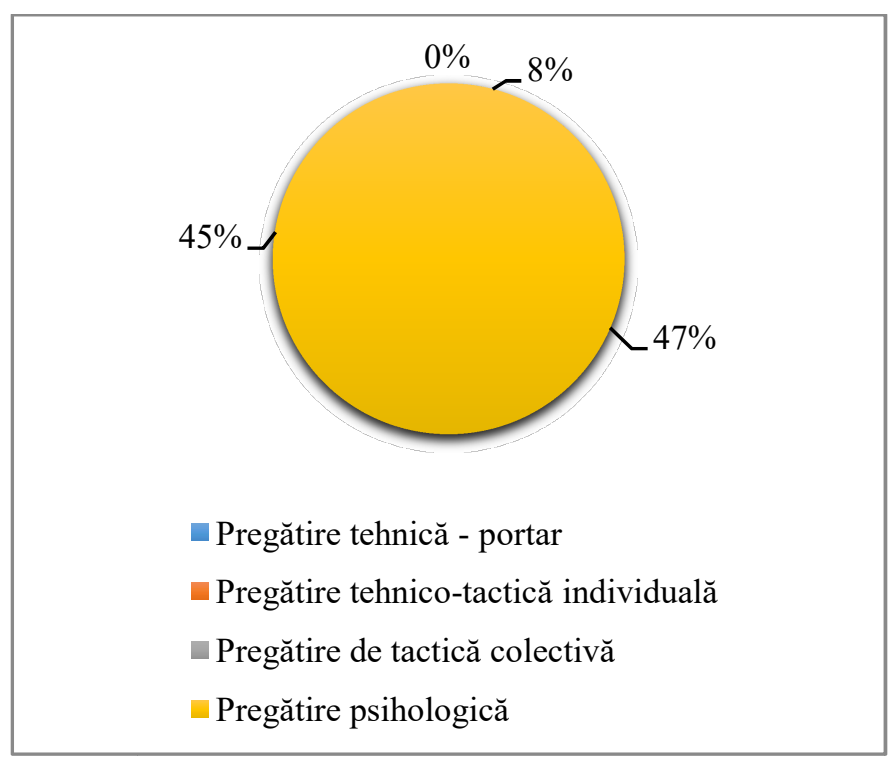

TECHNICAL TRAINING - GOALIE/ INDIVIDUAL TECHNICAL-TACTICAL TRAINING/ COLLECTIVE TACTICAL TRAINING / PSYCHOLOGICAL TRAINING

Figure 1.The weighting of the training components of Romania's ice hockey team. The specific preparatory period (technical and tactical)

In the month of March, the final selection was made, the team was summoned to centralised training inGalati, in the precompetitive stage, in order to train for the participation to the World Championship, Second Division, Group A, conducted in the period April 3-9, 2017 in Galați.

Centralised training was conducted according to an instruction strategy materialised in a tactical plan and the training microcycle was tailored for the precompetitive stage.

The tactical instruction strategy approached at the level of Romania's senior national ice hockey team - for the World Championship, Second Division, Group A, in the centralised training stage 27.03-02.04. 2017 - includes technical and tactical objectives, through a mix of methodical actions.

Following centralised training, the weighting of the technical-tactical and of the psychological practice within centralised training preserves more or less the same proportions as centralised training within clubs. Hence, the individual technical-tactical training elements accounted for the highest percentage, namely $62 \%$, for the same reason mentioned above: the one of improving the technical-tactical elements that must be executed perfectly at individual level and that represent a foundation of the collective tactical elements, accounting for $22 \%$ in this stage. The focus is less on the technical training of goalies; the percentage drops to $4 \%$, while psychological training occupies an important place in the training of players, namely $12 \%$ (Figure 2 ). In this period and form of training, the psychological component has an essential role within practices, because at this level of performance - besides the physical, technical, and tactical training - players' motivation, group cohesion, and determination make the difference in the attaining of high performances. 


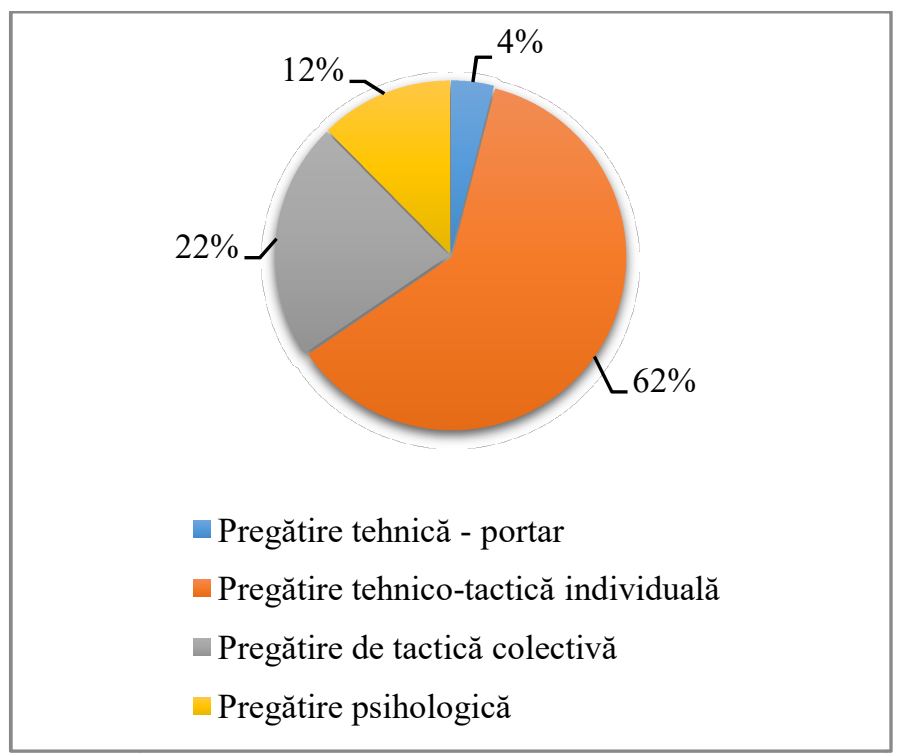

TECHNICAL TRAINING - GOALIE/ INDIVIDUAL TECHNICAL-TACTICAL TRAINING/ COLLECTIVE TACTICAL TRAINING / PSYCHOLOGICAL TRAINING

Figure 2. The weighting of the training components of Romania's ice hockey team. The precompetitive stage - centralised training (2017)

By cumulating the elements within the technical and tactical training and psychological training, the weighting within the competitive year 2017 preserves a significant proportion of individual technical and tactical training $-52 \%$, collective tactical training $-36 \%$, goalie's training $-7 \%$, while psychological training $-5 \%$ (Figure 3 ).

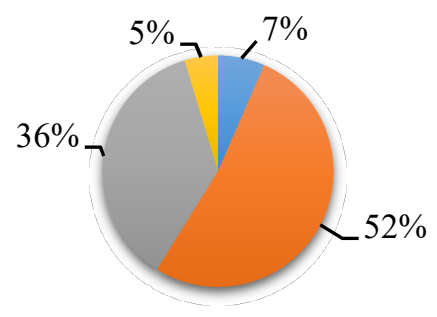

- Pregătire tehnică - portar

- Pregătire tehnico-tactică individuală

- Pregătire de tactică colectivă

Pregătire psihologică

TECHNICAL TRAINING - GOALIE/ INDIVIDUAL TECHNICAL-TACTICAL TRAINING/ COLLECTIVE TACTICAL TRAINING / PSYCHOLOGICAL TRAINING

Figure 3. The weighting of the training components of Romania's ice hockey team. The precompetitive and the competitive stage - centralised training

We conclude that - as we have proposed - the independent variable was implemented both within the clubs and within centralised training with the representative Romanian team. Hence, the proposed technical and tactical training strategy proposed was materialised in three microcycles, accounting for a total number of 67 hours (4,190 minutes) of training. 
The final selection of players from clubs for the representative Romanian team was done pursuant to their evolution in the play-offs. We have analysed the technical and tactical training strategies applied in the games, the involvement during matches, and the athletic form of the players at that point. Thus, we have realised that the short list for the representative Romanian team comprises athletes from ASC Corona Brașov, SC MiercureaCiuc, CSM DunăreaGalați, CSA SteauaBucurești, ProgymGheorgheni.

\section{Analysis of the results obtained at the 2017 World Championship}

Graphically, the results of Romania's hockey team at the 2017 World Championship are featured in comparison with those of the other teams in attendance, in Figure 4.

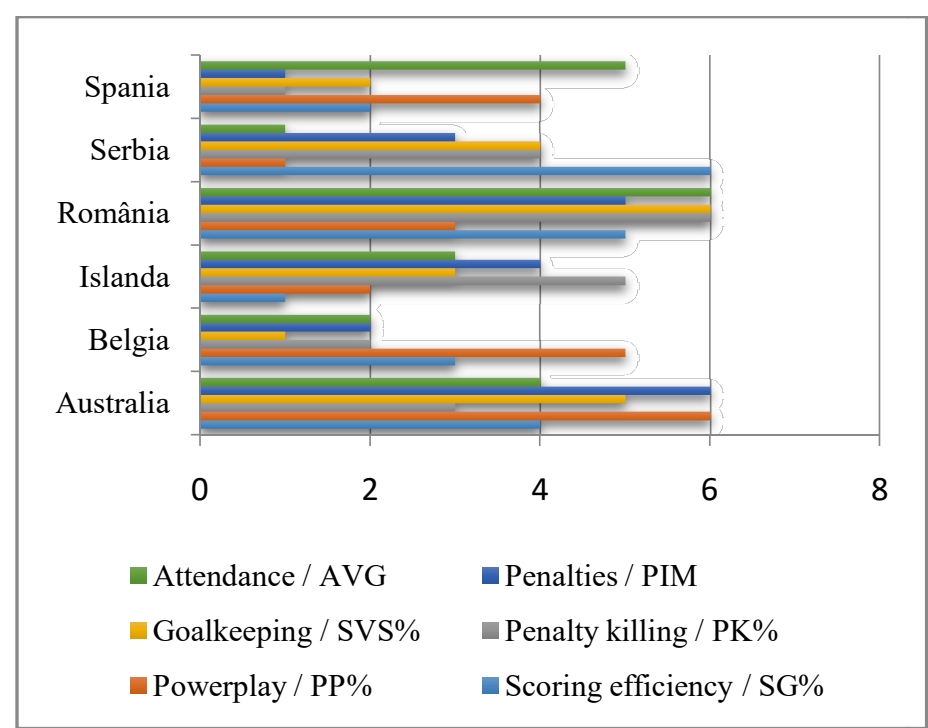

Figure 4. Comparative representation of performance indicators, 2017 WC, Second Division, Group A

The individual results of the wingers and the defencemen at the 2017 Ice Hockey World Championship are featured in Figures 5 and 6.

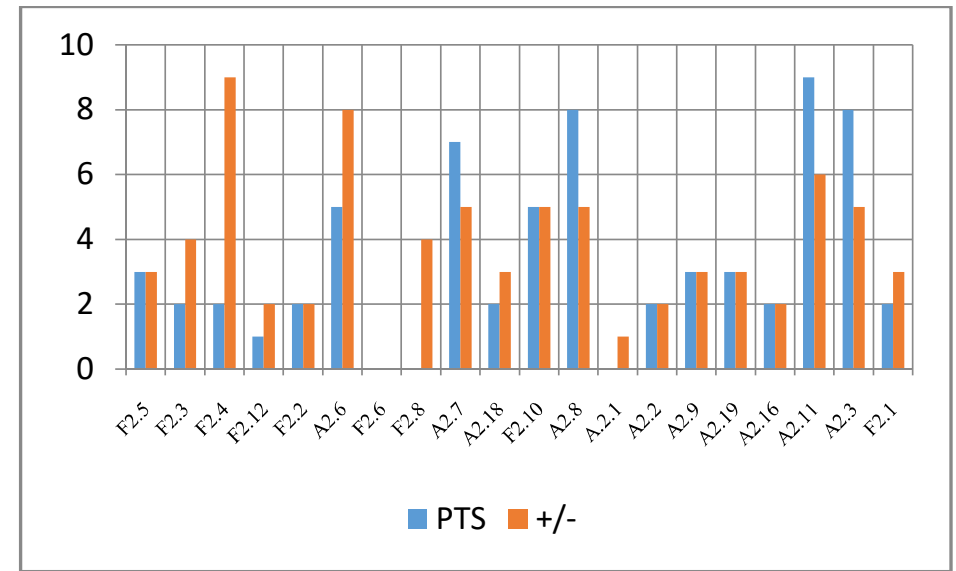

Figure 5. Total points +/- per player, Romania, 2017 WC, Second Division, Group A 


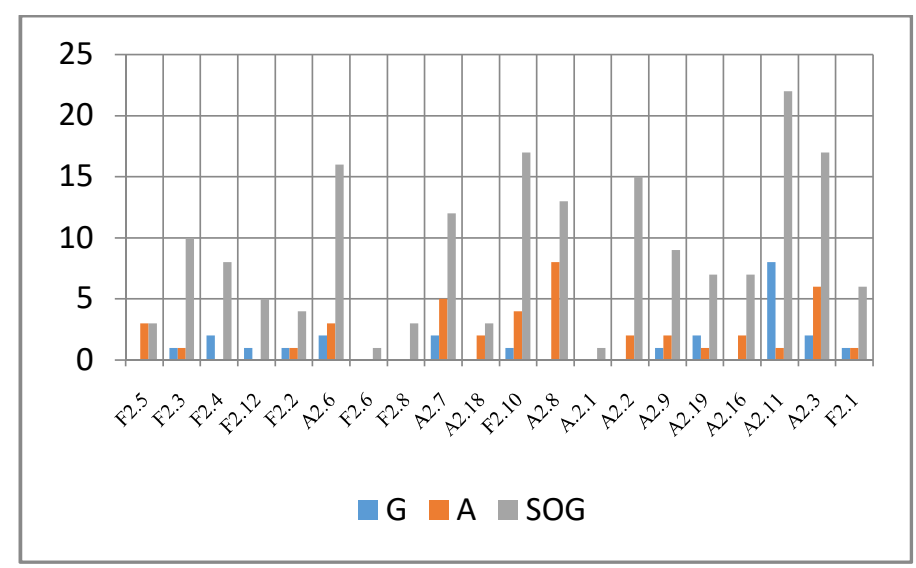

Figure 6. Goals, assistances, and shots on goal per player, Romania, 2017 WC, Second Division, Group A

It is apparent that the plus-minus difference (between the plus given to a player on ice when his team scores, in equal or inferior positions; and the minus given to the players on ice when the opponents score in the same situations) is positive for all the players of Romania's senior ice hockey team attending the 2017 World Championship, except for subject F2.6, for whom $+/-$ is 0 . From among the 20 wingers and defencemen, 17 players obtained at least one point, by scoring a goal or an assistance. The lowest number of points was accumulated by F.2.12 (1 point, by scoring a goal), while most A.2.11 by scoring 8 goals and achieving an assistance, also obtaining the best transformation rate of shots on goal into goals $(36.36 \%)$.

\section{Conclusions}

- Within the technical and tactical training program that we proposed, we have used complex and efficient actuation means, which have determined the improvement of technical executions and of tactical strategies specific to matches within a competition corresponding to the objective.

- Technical and tactical training was materialised into elements of individual tactics, technical training of the goalie, and elements of collective tactics. Hence, the highest percentage is ascribed to individual tactic exercises $(62 \%)$, followed by collective tactics $(22 \%)$ and goalie's training (4\%). Psychological training accounts for a higher percentage in the period before the competition corresponding to the objective (12\%).

- $\quad$ The performance of Romania's representative team at the ice hockey 2017 World Championship, Second Division, Group A is the outcome of two elements: the selection of the representative group and the training program designed and implemented (the independent variable of our research).

- $\quad$ Taking into account that - at the end of the competitive program - Romania's representative ice hockey team, seniors, won the World Championship and promoted to a superior group, we conclude that the training strategies designed, proposed, and implemented were indeed effective.

\section{Bibliography}

1. Alexe, Nicu (coordonator) (1993). Antrenamentul sportiv modern, Editura EDITIS, București, 531 pagini

2. Blanchard, Kendall (1995). The Antropology of Sport: an introduction, Bergin \& Garvin, 306 pagini

3. Crihan, Virgil (1977). Hochei: pregătirea copiilor şi juniorilor, Editura Sport-Turism, București, 194 pagini 
4. Crihan, Virgil (1982). Hochei pe gheață, Editura Sport- Turism, Bucureşti, 264 pagini

5. Dragnea, Constantin Adrian; Mate-Teodorescu, Silvia (2002). Teoria sportului, FEST, București, 628 pagini

6. Dragnea, Adrian, Bota, Aura,Teodorescu, Silvia, Stănescu, Monica, Şerbănoiu, Sorin, Tudor, Virgil (2006). Educaţie fizică şi sport: teorie şi didactică, Editura FEST, Bucureşti, 300 pagini

7. Hockey Canada, https://www.hockeycanada.ca, accesat la 23.07.2017

8. Joyce, David; Lewindon, Daniel (editori) (2014). High Performance Training for Sports, Human Kinetics, 377 pagini

9. Platonov, Vladimir Nikolaevici (2015). Periodizarea antrenamentului sportiv: teoria generală şi aplicațiile ei practice, Editura Discobolul, București, 607 pagini

10. Platonov, Vladimir Nikolaevici (2001). Teoría general del entrenamiento deportivo olímpico, Editorial Paidotribo, 687 pagini 